\title{
Micromechanical testing of oxidised grain boundaries in Ni Alloy 600
}

\author{
Alisa Stratulat ${ }^{1}$ and Steve G. Roberts ${ }^{1}$ \\ ${ }^{1}$ Department of Materials, University of Oxford, UK
}

\begin{abstract}
Micromechanical testing of focused ion beam (FIB) machined cantilevers was used to study oxidised grain boundaries in Ni-alloy 600. The Ni-alloy 600 samples were exposed in simulated PWR primary water at $325^{\circ} \mathrm{C}$ for $4500 \mathrm{~h}$ with a hydrogen partial pressure of $30 \mathrm{kPa}$. The FIB was used to machine small cantilever beams at the selected sites in the Ni alloy 600, cut so that the beam contained a selected grain boundary close to the built-in end. The FIB was also used to make a pre-crack, $700 \mathrm{~nm}$ deep, on the grain boundary. Cantilevers were loaded at the free end using a nanoindenter. Cantilevers milled in the un-oxidised sample yielded, and did not fracture. The specimens containing oxidised grain boundaries fractured at the boundary after small amounts of plasticity. Load vs. displacement data were used to calculate the fracture toughness of the oxidised grain boundaries. The fracture toughness associated with fracture of grain boundary oxide for these cantilevers was in the range $0.73-1.82 \mathrm{MPa}(\mathrm{m})^{1 / 2}$, with an average value of $1.3 \mathrm{MPa}(\mathrm{m})^{1 / 2}$. We believe this to be the first time the fracture toughness of an oxidised grain boundary has been determined.
\end{abstract}

\section{INTRODUCTION}

Stress Corrosion Cracking (SCC) involves a highly complex interplay of diffusional, chemical and mechanical factors in a series of related mechanisms, and affects material performance in a wide range of materials systems and environments. Within the nuclear industry where safety and structural integrity are crucial concerns SCC is of great significance; in particular in some Ni based alloys, and in austenitic stainless steels. In such systems SCC is predominantly along grain boundary paths. Alloy 600 is a solution strengthening alloy of composition $75 \% \mathrm{Ni}, 15 \% \mathrm{Cr}$ and $7 \% \mathrm{Fe}$ [1]. Ni Alloy 600 mainly fails intergranularly in the pressurized water reactor (PWR) environment [2] in the steam generator tubes [3-4]. One of the causes of intergranular cracking is the degradation of grain boundaries by oxidation. This study will describe a method recently developed to determine the fracture toughness of individual oxidised grain boundaries in Ni Alloy 600, following the work of Di Maio and Roberts on microcantilever fracture of silicon and WC coatings [5], and that of Armstrong, Wilkinson and Roberts on fracture of bismuth embrittled grain boundaries in copper [6].

\section{EXPERIMENTAL DETAILS}

Ni Alloy 600 samples provided by AREVA were first polished down to a $1 \mu \mathrm{m}$ diamond finish and then exposed in PWR primary water at $325^{\circ} \mathrm{C}$ for $4500 \mathrm{~h}$ with a hydrogen partial pressure of $30 \mathrm{kPa}$. Lastly, the samples were polished with colloidal silica, which also revealed the intergranular oxide. Oxidised grain boundaries were examined by cutting FIB trenches and the ones perpendicular to the surface were selected for cantilever production. FIB was used to machine small, pentagonal cross-section cantilevers ( $5 \mu \mathrm{m}$ wide by $25 \mu \mathrm{m}$ long), cut so that the 
beam contained, close to the build-in end, a selected grain boundary as in Figure 1. Cantilevers were pre-notched at the grain boundary using a FIB single cut of 700nm depth.

An MTS Nanoindenter XP System was used to perform AFM-type scans to image the cantilevers, and then to load them close to the free end. Load vs. displacement data were used to calculate the fracture toughness of different oxidised grain boundaries.

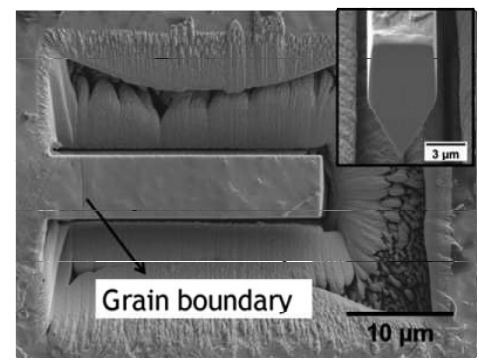

Figure 1. FIB machined cantilever in Ni alloy 600 with a pentagonal cross section.

Fracture toughness was calculated (as by Di Maio[5]) using the dimensions of the cantilever and the load at which the cantilever failed, via the following equation:

$$
K_{I_{c}}=\frac{P L y}{I} \sqrt{\pi a} F\left(\frac{a}{b}\right),
$$

where $\mathrm{P}$ is the load applied by the nanoindenter, $\mathrm{L}$ is the length from the grain boundary to the loading point, a is the depth of the notch and I is the moment of inertia of the beam cross section. I is calculated as:

$$
I=\frac{w b^{3}}{12}+\left(y-\frac{b}{2}\right)^{2} b w+\frac{w^{4}}{288}+\left[\frac{b}{6}-(b-y)\right]^{2} \frac{w^{2}}{4},
$$

where $\mathrm{w}$ and $\mathrm{b}$ are the dimensions shown in Figure 2 and $\mathrm{y}$ is defined as:

$$
y=\frac{\frac{b^{2} w}{2}+\frac{w^{2}}{4}\left(b+\frac{w}{6}\right)}{b w+\frac{w^{2}}{4}}
$$

F given in Eq. (1) is approximated to be:

$$
F\left(\frac{a}{b}\right)=1.85-3.38\left(\frac{a}{b}\right)+13.24\left(\frac{a}{b}\right)^{2}-23.26\left(\frac{a}{b}\right)^{3}+16.8\left(\frac{a}{b}\right)^{4}
$$

The cantilevers were imaged using a Scanning Electron Microscope and the fracture surface was observed. 


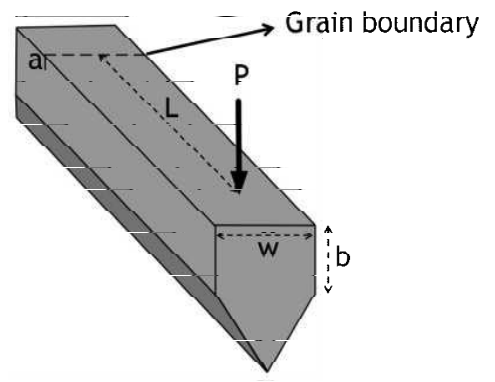

Figure 2. Geometry and dimensions of the cantilevers used in the study.

\section{RESULTS}

\section{$\underline{\text { Sample exposed for } 4500 \mathrm{~h}}$}

Load vs. displacement curves for two different cantilevers are presented in Figure 3. The load vs. displacement curve indicates fracture of the cantilevers, which is confirmed by micrographs of the cantilevers that were taken after the tests, shown in Figure 4.
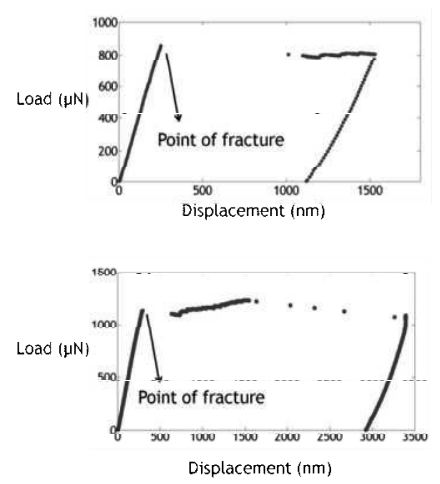

Figure 3. Load vs. displacement data for oxidised grain boundaries showing fracture, a rapid displacement increase at a critical load.
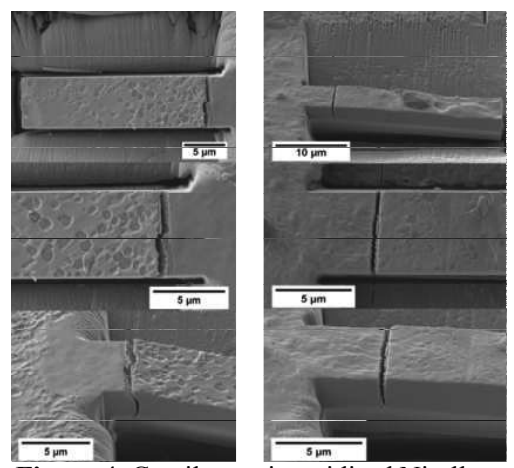

Figure 4. Cantilevers in oxidised Ni-alloy, after testing, showing fracture at the oxidised grain boundary.

The results for 22 tested cantilevers are presented in Figure 5. The fracture toughness associated with fracture of grain boundary oxide for these cantilevers was in the range of 0.73 $1.82 \mathrm{MPa}(\mathrm{m})^{1 / 2}$, with an average value of $1.3 \mathrm{MPa}(\mathrm{m})^{1 / 2}$. The thickness of the intergranular oxide was measured using the Scanning Electron Microscope. It can be observed from Figure 5 that 
there is a weak correlation between the oxide thickness and the fracture toughness value, such that the grain boundaries become weaker with increasing oxide thickness.

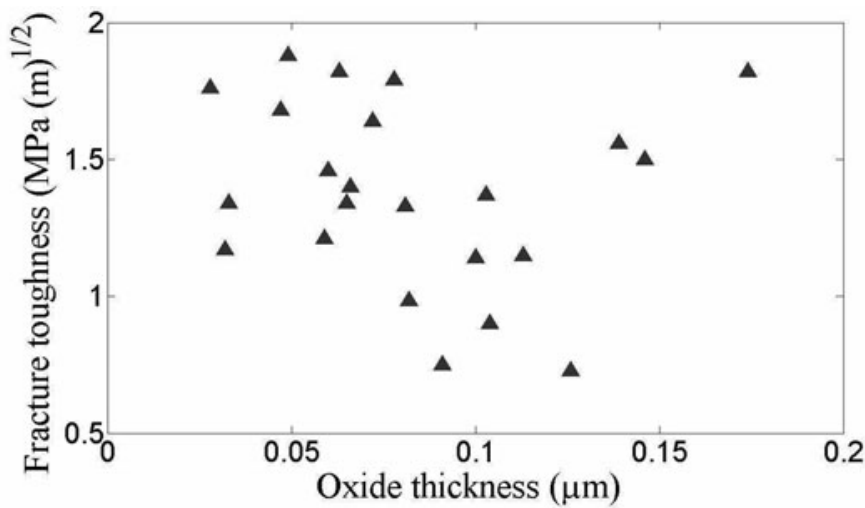

Figure 5. Calculated fracture toughness for tested cantilevers vs. oxide thickness.

Fracture surfaces were observed using the Scanning Electron Microscope and are shown in Figure 6.
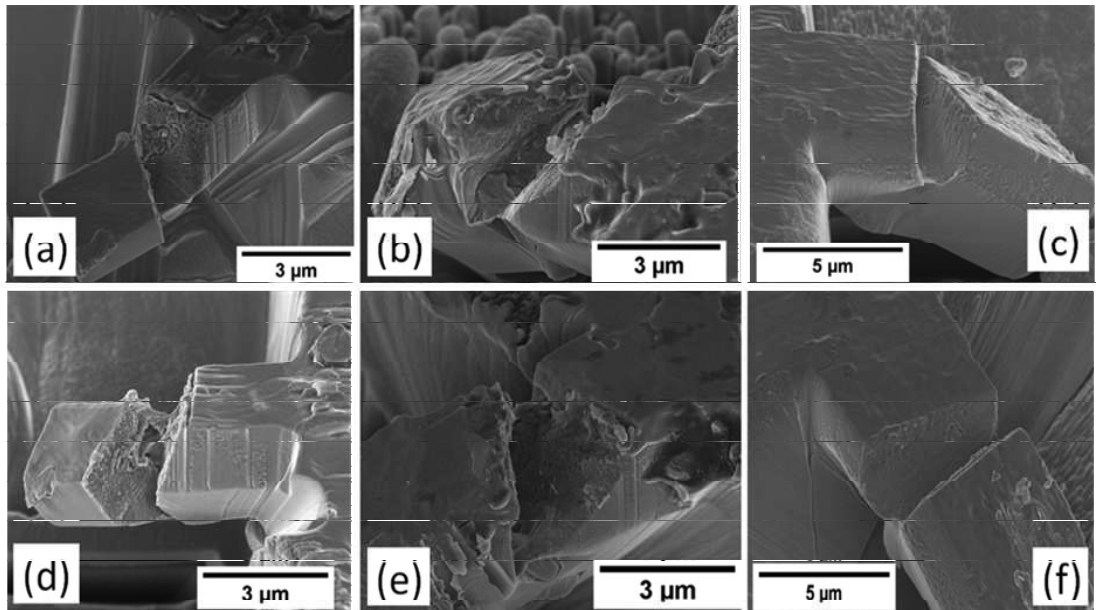

Figure 6. A discussion of different fracture surfaces at different toughness values. The fracture toughness values, are: $(\mathrm{a}, \mathrm{d}) 0.73 \mathrm{MPa}(\mathrm{m})^{1 / 2},(\mathrm{~b}, \mathrm{e}) 1.64 \mathrm{MPa}(\mathrm{m})^{1 / 2}$ and $(\mathrm{c}, \mathrm{f}) 1.82 \mathrm{MPa}(\mathrm{m})^{1 / 2}$. 


\section{$\underline{\text { Un-oxidised sample }}$}

Load vs. displacement curve for one of the six tested cantilevers made in un-oxidised Ni-alloy 600 is presented in Figure 7. The load vs. displacement curve is typical for a plastically deformed cantilever. The curve has initial elastic loading, yield and then plastic deformation. Figure 8 shows a micrograph of such a cantilever after testing: no fracture has occurred, but slip bands are present.

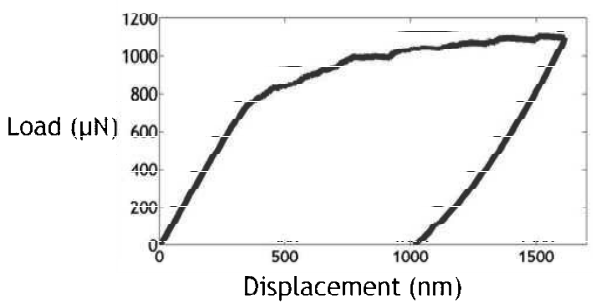

Figure 7. Load vs. displacement data for an un-oxidised cantilever, showing no fracture.

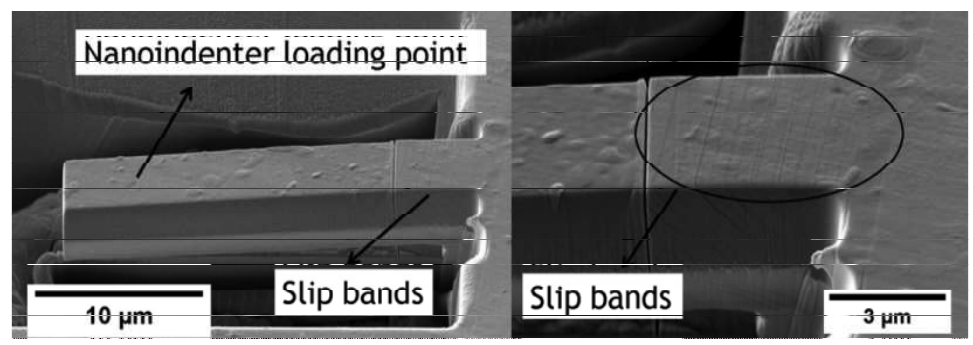

Figure 8. Cantilever after testing in un-oxidised Ni-alloy, showing slip bands (indicated by the arrow).

\section{CONCLUSIONS}

This study is believed to be the first that determines the fracture toughness of an oxidised grain boundary. The method described is a valid testing method for determining grain boundary strength in SCC susceptible alloy. Cantilevers milled in un-oxidised specimens yielded, and did not fracture. The specimens containing oxidised grain boundaries fractured at the boundary after small amounts of plasticity. The fracture toughness associated with fracture of grain boundary oxide for tested cantilevers was in the range of $0.73-1.82 \mathrm{MPa}(\mathrm{m})^{1 / 2}$, with an average value of $1.3 \mathrm{MPa}(\mathrm{m})^{1 / 2}$. 


\section{ACKNOWLEDGEMENTS}

The author would like to thank to D.E.J. Armstrong for his help in exposing the fracture surfaces, Olivier Calonne and Marc Foucault from AREVA for providing the specimens and for useful suggestions and discussions. The research was supported by AREVA and the Engineering and Physical Science Council (EPSRC).

\section{REFERENCES}

1. R. S. Dutta, Journal of Nuclear Materials 393, 343-349 (2009).

2. A. Aguilar, J. L. Albarran, H. F. Lopez and L. Martinez, Materials Letters 61, 274-277 (2007)

3. R. B. Rebak and Z. Szklarska-Smialowska, Corrosion Science 38, 971-988 (1996)

4. J. Panter, B. Viguier, J. M. Cloue, M. Foucault, P. Combrade and E. Andrieu, Journal of Nuclear Materials 348, 213-221 (2006)

5. D Di Maio and SG Roberts, Journal of materials research 20, 299-302 (2005)

6. D.E.J. Armstrong, A.J. Wilkinson and S.G. Roberts, Philosophical Magazine Letters 91, 394$400(2011)$ 